\title{
ASSISTÊNCIA DE ENFERMAGEM AOS RECÉM-NASCIDOS EM FOTOTERAPIA
}

Ruth Natalia Teresa Turrini*

TURRINI, R.N.T. Assistência de enfermagem aos recém-nascidos em fototerapia. Rev. Esc. Enf. USP, São Paulo, 22 (3): 309-321, dez. 1988.

A au tora fez um levantamento bibliográfico sobre mecanismo de açāo, efeitos colaterais e tipos de lâmpadas usadas na fototerapia. Descreveu a assistencia de enfermagem prestada aos recém-nascidos em fototerapia no Berçurio de Recém-Nascidos Externos do Institu to da Criança do Hospital das Clínicas da Faculdade de Medicina da Universidade de Säo Paulo.

UNITERMOS : Recém nascidos. Fototerapia. Assistência de enfermagem.

\section{INTRODUÇÃO}

Em 1958, em Essex, na Inglaterra, a equipe de enfermagem do berçário notou que as crianças mais próximas da janela eram menos ictéricas do que as que permaneciam em locais mais escuros, e percebeu a diminuição da pigmentação amarela quando as crianças eram expostas por curtos períodos à luz do dia.

A partir dai, Cremer, citado por $\mathrm{BROWN}^{3}$, relata que o nível sérico de bilirrubina de recém-nascidos ictéricos era altamente fotossensível, isto $\hat{e}$, quando recém-nascidos eram expostos por uma hora à luz, o nível de bilirrubina diminuía em $30 \%$. Este método, na época, foi muito criticado pois duvidava-se de sua eficácia e não havia informaçðes sobre possíveis efeitos colaterais.

Desde que Lucey, mencionado por TUFTS \& JOHNSON ${ }^{25}$ demonstrou a eficácia da fototerapia, esta vem sendo amplamente utilizada no tratamento e prevenção da hiperbilirrubinemia, tanto em crianças de termo quanto de pré-termo. Apesar de serem conhecidas complicações decorrentes de seu uso, poucas consequências, a longo prazo, foram descritas ${ }^{12}$, na literatura consultada.

Certamente, o uso da fototerapia modificou profundamente o andamento do tratamento da doença hemolítica do recém-nascido, reduzindo notavelmente a necessidade da exsangúíneo transfusão ${ }^{17}$.

$O$ presente estudo baseia-se num levantamento bibliográfico sobre a fototerapia e inclui a assistência de enfermagem prestada aos recem-nascidos que fazem uso dessa te rapêutica no Instituto da Criança citado.

* Enfermeira do Berçário de Recém-Nascidos Externos do Instituto da Criança do Hospital das Clínicas da Faculdade de Medicina da Universidade de São Paulo. 


\section{Mecanismo de ação da fototerapia}

Estudos recentes mostram que a fototerapia aumenta a excreção de bilirrubina e que a capacidade dos pigmentos biliares absorverem a luz depende de sua estrutura molecular.

O comprimento de onda da luz mais efetivo na diminuição dos níveis séricos de bilirrubina é o que se encontra entre 440 e $470 \mathrm{~nm}$ (nanômetro). Desde que o comprimento de onda mais efetivo para a fototerapia corresponde ao pico de absorção de bilirrubina na pele e nos tecidos periféricos, pode-se deduzir que a excreção é devida a reações fotoquímicas nas quais a bilirrubina é o fotoreceptor ${ }^{3}$.

As substâncias derivadas da bilirrubina excretadas na urina durante a fototerapia são incolores e, provavelmente, de baixo peso molecular em relação à bilirrubina. As excretadas na bile são coloridas e tomam a bile mais escura durante a fototerapia. Associado à hiperpigmentação, há aumento aparente da concentração de bilirrubina não conjugada na bile ${ }^{3}$.

Com a exposição à luz, a pele do recém-nascido perde a cor amarela, havendo diminuição da concentração de bilirrubina sérica. Parece haver processos distintos responsáveis por estes efeitos tais como:

1 - fotoxidação: quebra da molécula de bilirrubina em compostos mais polares e hidrossolúveis e facilmente excretados na bile e fezes, e em menor quantidade na urina, fotoxidação essa que envolve $\mathrm{O}_{2}$ livre (fotoxidação aeróbica) ${ }^{13,15} ; \mathrm{e}$

2 - fotoisomerização: $\mathrm{McDONAGH}^{13}$, a fotoxidação da bilirubina é lenta e ineficiente, pois ela tem de competir com duas reações mais rápidas em que a forma da molécula é modificada mas não fragmentada, denominada lumirubina (isômero estrutural). Esta não se acumula no organismo a não ser que a função hepatobiliar esteja anormal.

Além disto, há uma reação configuracional ou geométrica responsável por $80 \%$ da eficácia da fototerapia. A bilirrubina IX $-\alpha(Z, Z)$ sofre fotoisomerização rápida e reversivel para formar isômeros $\mathrm{ZE}, \mathrm{EZ}$ e EE, que são mais polares, menos lipofilicos e mais ácidos do que os isômeros $\mathrm{ZZ}$ naturais ${ }^{1,15}$. te maneira:

McDONAGH ${ }^{13}$ esquematizou os mecanismos de ação da fototerapia da seguin-

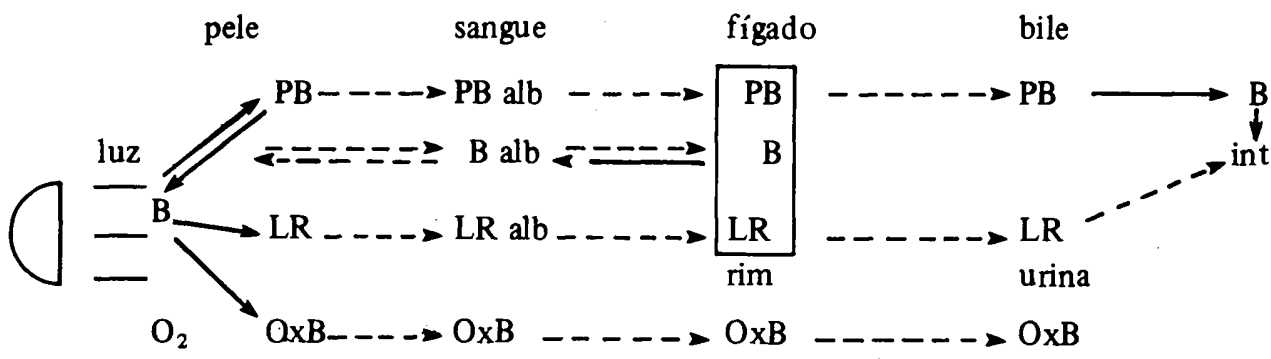

B - bilirrubina ( $\mathrm{ZZ}$ isômero)

LR - lumirubina ( $E$ e $Z$ isômeros)

$\mathrm{O} \times \mathrm{B}$ - produtos foto-oxigenados

$\mathrm{PB}$ - fotobilirrubina (EE e EZ isômeros) 
Todas as reações são reversíveis no escuro e são lentas quando ligadas à albumina, mas ocorrem rapidamente quando o pigmento está dissolvido na bile ${ }^{13}$. Conforme $\mathrm{COSTARINO}^{6}$, a formação da lumirubina é irreversível.

Segundo os estudos de BRYLA ${ }^{4}$ a fototerapia é mais efetiva nas primeiras 24 a 48 horas de uso.

A absorção de luz pela bilirrubina presente na pele leva primeiramente à formação de bilirrubina fotoxidada, que tem uma meia vida de menos de cinco minutos. Um rearranjo molecular de bilirrubina fotoxidada leva à formação de isômeros geométricos, assim como do isômero estrutural Z-lumirubina. Estes pigmentos são transportados no plasma e podem ser excretados na bile sem requerer a conjugação com o diglicuronídio; eles ultrapassam o passo do metabolismo que é deficiente no neonato (isto é, conversão da bilirrubina "natural" não conjugada em bilirrubina diglicuronidio) e a excreção pode ocorrer sem a glicuronil transferase.

No intestino, os fotoisômeros são termicamente menos estáveis que a bilirrubina natural e provavelmente são revertidos à forma natural, um isômero lipofílico mais estável; são reabsorvidos pela circulação enterohepática e contribuem novamente para a bilirrubina a ser excretada pelo fígado. Isto explicaria porque o nível de bilirrubina sérica aumenta após o uso da fototerapia ou depois de 24 a 48 horas.

\section{Características da fonte de luz e dosagem de luz}

\subsection{Tipos de lâmpadas}

As lâmpadas mais efetivas para a fotoxidação da bilirrubina são as que apresentam al ta produção de energia emitida próxima ao pico máximo de absorção da bilirrubina, ou seja, entre 450 e $460 \mathrm{~nm}$. Parece ser necessário um fluxo mínimo de $4 \mathrm{~W} /\left(\mathrm{cm}^{2} . \mathrm{nm}\right)$ para uma fototerapia efetiva e a resposta aumenta com o aumento da dose até que o ponto de saturação seja atingido, além do qual não pode ser demonstrada nenhuma resposta adicional ${ }^{1}$.

Vários tipos de luz fluorescente têm sido usados: amplo espectro, luz dia, luz fria, luz azul ou "azul especial" e luz verde.

O esquema abaixo mostra as características da emissão espectral de lâmpadas fluorescentes usadas em fototerapia conforme mencionam AVERY ${ }^{1}$ e VECCHI ${ }^{26}$ :

$\begin{array}{lcc}\text { lâmpada } & \text { faixa }(\mathrm{nm}) & \text { pico principal }(\mathrm{nm}) \\ \text { luz dia } & 380-700 & 550-600 \\ \text { luz branca fria } & 380-700 & 550-600 \\ \text { luz azul } & 335-600 & 425-475 \\ \text { huz azul especial } & 420-480 & 420-480 \\ \text { luz verde } & 500-570 & 525\end{array}$

Embora a luz azul seja mais efetiva do que a branca, pouco se conhece sobre os efeitos colaterais da luz monocromática, uma vez que as experiências, na maioria foram feitas com a luz de amplo espectro. A luz azul não permite boa avaliação da cor 
da pele da criança e pode conduzir à não detecção de cianose ${ }^{1}$. A luz especial azul mostrou ser a mais eficaz de todas em reduzir os níveis de bilirrubina indireta, porém causa cefaléia, náuseas e vertigens na equipe atuante no cuidado a essas crianças ${ }^{25}$.

Em 1982, VECCHI ${ }^{26}$ realizou um estudo com a luz verde em prematuros ictéricos, tendo observado que esta era mais eficaz que a luz natural, não apresentava efeitos colaterais a curto prazo, era mais segura, tolerável e diminuía o risco de lesão de retina para medicos e equipe de enfermagem.

Em 1985, ENNEVER ${ }^{9}$ discutiu o uso da luz verde, pois esta reduziria o foto equilíbrio na proporção de fotoisômeros, levando a formação de bilirrubina "natural".

Também em 1985, VECCHI et aliii ${ }^{27}$ fizeram um novo estudo em prematuros ictéricos nos quais observou a eficácia da luz verde e azul especial na fototerapia. Se em ratos Gunn, o principal mecanismo é a fotodegradação da bilirrubina em isômeros configuracionais, em crianças, o mecanismo principal seria a formação de lumirubina, que é rapidamente eliminada pelo organismo. Isto explicaria a eficácia da luz verde.

As luzes usadas geralmente na fototerapia emitem "range" (comprimento de onda) entre 400 e $700 \mathrm{~nm}$, e os raios ultravioletas são filtrados pelo plexiglass (RUV $<350 \mathrm{~nm}$ ). No entanto, estudos in vitro demonstraram que ondas mais longas (350- $450 \mathrm{~nm}$ ) seriam mutagênicas para as células procarióticas e eucarióticas, e, além do mais, seriam carcinogênicas. Por isso, tem-se recomendado o uso da luz verde que emite ondas acima de $500 \mathrm{~nm}^{26,27}$.

\subsection{Duração das lâmpadas}

A luz fria branca mantêm-se estável em termos de energia liberada por aproximadamente 2000 horas, enquanto que a luz azul torna-se ineficaz após 200 horas de uso. Pode-se também avaliar a eficácia das lâmpadas pela medida do fluxo radiante que deve permanecer em torno de $6 \mathrm{~W} /\left(\mathrm{cm}^{2} . \mathrm{nm}\right)^{11}$.

\subsection{Distância das lâmpadas}

Recomenda-se que a criança seja colocada a mais ou menos $40 \mathrm{~cm}$ da fonte de luz. Aumentando-se a distância entre as lâmpadas e a superfície corpórea da criança, ocorre diminuição da eficácia da "energia" emitida pelas lâmpadas ${ }^{13}$.

MODI E KEAY ${ }^{14}$ fizeram um estudo para saber qual a importância da dosagem de luz na fototerapia. Os resultados mostraram que, quanto mais próxima da criança a fonte de luz, menor foi a exposição da criança à luz, pois a radiância varia inversamente com o quadrado da distância.

Em 1984, EGGERT et alii ${ }^{8}$ estudaram a distribuição da intensidade da luz na incubadora. A heterogeneidade da intensidade da luz era tanto maior quanto mais próxima a lâmpada estivesse do colchão. Devido a esta distribuição, houve aumento na intensidade da luz no centro da incubadora quando se deslocou o colchão da posição $47 \mathrm{~cm}$ para $27 \mathrm{~cm}$; nas regiōes periféricas só aumentou em um quinto. Quando se cobriu a incubadora com um pano que refletia a luz a $47 \mathrm{~cm}$, o poder irradiante em todos os pontos aumentou e produziu maior distribuição da luz. Ao contrário da ilumina- 
ção direta, o poder de irradiação diminui quanto mais próxima do colchão estiver a luz refletida, além de manter-se uma distribuição heterogênea.

\subsection{Area exposta}

Quanto maior a área cutânea exposta, maior a efetividade da fototerapia ${ }^{11}$.

\subsection{Tempo de uso e modo de iluminação}

A literatura não é uniforme em relação ao uso da fototerapia contínua ou intermitente. Os defensores desta última preconizam a redução do tempo de exposição à luz mantendo a mesma efícácia e diminuindo os seus efeitos colaterais. Por outro lado há evidências laboratoriais in vitro, mostrando ação deletéria maior da fototerapia intermitente em relação à alteração do DNA celular.

Conforme menciona PALUDETTO et alii ${ }^{17}$, Vogh expôs recém-nascidos ictéricos por 15 minutos à fototerapia, intercalados com uma hora sem esse tratamento, tendo observado que o uso da fototerapia foi tão eficaz quanto no tratamento contínuo. Isto se deve ao fato de ser de uma a três horas o tempo para substituição, na pele, de uma molécula de bilirrubina ativada por uma não ativada pela luz.

Sendo assim, esquemas de fototerapia intermitente, com intervalos de 6 a 12 horas, teriam a mesma eficácia que a contínua.

SHARMA et alii ${ }^{20}$ estudou os efeitos da fototerapia da superfície dupla e de superfície única na hiperbilirrubinemia neonatal. $\mathrm{Na}$ fototerapia, de superfície dupla, a criança recebeu luz nas regiões dorsal e ventral ao mesmo tempo; constatou que houve considerável diminuição do nivel sérico de bilirrubina após 12 horas, número inferior de horas que a criança precisaria ficar exposta à fototerapia de superfície única para serem obtidos os mesmos resultados.

\section{Eficácia da fototerapia}

Nos casos em que não ocorre hiperhemólise; a fototerapia reduz os niveis de bilirrubina em 1 a $2 \mathrm{mg} / 100 \mathrm{ml}$ após 12 horas de exposição à luz.

\section{Indicaçðes para fototerapia}

O principal uso da fototerapia é na prevenção e tratamento da hiperbilirrubinemia. A fototerapia reduziu significantemente o uso da exsangüíneo transfusão em crianças com Coombs negativo ${ }^{3}$. Na doença hemolítica, a fototerapia é indicada apenas como tratamento auxiliar da exsanguíneo transfusão, não devendo ser usada para substituíla quando pré-existir indicação para esta.

Sabe-se, atualmente, que são imprecisos os níveis críticos para a instalação de "kernicterus", sendo mais suscetíveis os recém-nascidos de menor peso e menor idade gestacional; portanto, a literatura tem preconizado niveis de bilirrubina cada vez menores para a utilização de fototerapia. 
GOSHI $^{11}$ compôs a tabela abaixo, na tentativa de diminuir os efeitos nocivos da hiperbilirrubinemia sobre o sistema nervoso central.

\section{TABELA 1}

NIVEIS DE BILIRRUBINA INDIRETA PARA INDICAÇÃO DA FOTOTERAPIA. (GOSHI ${ }^{11}$ )

\begin{tabular}{ccc}
\hline $\begin{array}{c}\text { Peso ao } \\
\text { nascer } \\
\text { (gramas) }\end{array}$ & $\begin{array}{c}\text { Com hemólise* } \\
\text { ou } \\
\text { complicaçoes** }\end{array}$ & $\begin{array}{c}\text { Sem hemólise } \\
\text { ou } \\
\text { complicações }\end{array}$ \\
\hline $\mathrm{P}<1500$ & $4 \mathrm{mg} / 100 \mathrm{ml}$ & $6 \mathrm{mg} / 100 \mathrm{ml}$ \\
$1500<\mathrm{P}<2000$ & $6 \mathrm{mg} / 100 \mathrm{ml}$ & $8 \mathrm{mg} / 100 \mathrm{ml}$ \\
$2000<\mathrm{P}<2500$ & $8 \mathrm{mg} / 100 \mathrm{ml}$ & $10 \mathrm{mg} / 100 \mathrm{ml}$ \\
$\mathrm{P}>2500$ & $10 \mathrm{mg} / 100 \mathrm{ml}$ & $12 \mathrm{mg} / 100 \mathrm{ml}$ \\
\hline
\end{tabular}

$\left.{ }^{*}\right) \quad$ Hemólise: hema tócrito $<45 \%$

(**) Complicações: acidose metabólica, insuficiência respiratória com hipoxemia, anóxia neonatal, hiperalbuminemia, hipoglicemia, hipotermia, jejum prolongado.

\section{Contra-indicações da fototerapia}

Segundo KATCHER ${ }^{12}$, a fototerapia é contra-indicada nos casos de:

- porfiria: os pacientes sofrem exacerbação dos sinais e sintomas;

- hiperbilimubinemia direta: pode indicar doença hepática com colestase ;

- eritroblastose fetal: deve-se fazer a exsanguíneo transfusão.

\section{Efeitos colaterais da fototerapia}

Apesar de vários estudos prospectivos e retrospectivos não terem demonstrado riscos graves ou efeitos indesejáveis permanentes do uso desta terapêutica, foram assinalados muitos efeitos colaterais transitórios. Alguns destes efeitos foram atribuidos direta ou indiretamente a exposição a luz. Outros, no entanto, continuam sem explicação definitiva ${ }^{21}$.

Os estudos até hoje feitos, colocando à prova a toxicidade dos produtos da degradação da bilirrubina sob ação da luz, tanto in vitro quanto in vivo, têm mostrado dois tipos de conclusð̃es:

- in vitro: há grande número de alteraçðes bioquímicas de proteínas e aminoácidos,, lípides, vitaminas e DNA, não havendo demonstração de manifestações clínicas relacionadas a essas alterações;

- in vivo: há grande número de alterações cujas manifestaçðes clínicas e possíveis consequências também não estão ainda identificadas ${ }^{10}$.

Cerca de um quinto das crianças em fototerapia apresentam letargia, distensão abdominal, diarréia e "rash" cutâneo (erupção). 
Abaixo são referidos os principais efeitos colaterais descritos na lite ratura.

\subsection{Bronzeamento}

Decorre da indução da síntese de melanina pela absorção de raios ultravioletas. Para evitá-lo é conveniente interpor-se uma placa de plexiglass (acrílico) entre a criança e a fonte de luz, com a finalidade de filtrar os raios ultravioletas. Com o mesmo propósito, e também para prevenir possível acidente, causado pela explosão das lâmpadas, o recém-nascido deve ser colocado dentro da incubadora ${ }^{11}$.

\subsection{Erupção cutânea}

Trata-se de um exantema máculo-papular observado em zonas expostas e decorre de fotossensibilidade da pele aos raios de luz, resultante da liberação de histamina pelos mastócitos ${ }^{11}$.

\subsection{Queimadura}

Ocorre pela excessiva exposição da pele à emissão de ondas curtas pelas lâmpadas fluorescentes $^{11}$. O plexiglass entre a criança e a luz elimina a passagem de ondas cur$\operatorname{tas}(200-280 \mathrm{~nm})$ e medias $(280-320 \mathrm{~nm})^{1}$.

\subsection{Perda de liquidos, termo-regulação e fluxo sanguiineo}

Há aumento da perda insensível de água. No recém-nascido de termo há aumento da perda de água de $40 \%$, enquanto nos pré-termos essa perda varia de 80 a $190 \%{ }^{1}$.

A temperatura corpórea pode elevar-se devido à energia térmica irradiada pelas lâmpadas ${ }^{11}$. Em comprimentos de ondas superiores a $650 \mathrm{~nm}$ (que incluem a energia infravermelha), observa-se que a maior parte da energia é absorvida pelo plexiglass. Isto pode aumentar a temperatura do próprio plexiglass e portanto da incubadora.

Ocorre, também, aumento do fluxo sanguíneo na pele e em menor grau no fluxo sanguíneo muscular ${ }^{1}$.

Os estudos de WALTHER ${ }^{28}$, em recém-nascidos de termo, mostram aumento da freqưuência cardíaca, porém insignificante, enquanto que nos recém-nascidos de prétermo a frequência cardíaca não se altera.

AVERY $^{1}$ relata aumento na frequência respiratória.

\subsection{Efeitos sobre a retina}

Há degeneração da retina quando esta é exposta à luz contínua. Conforme menciona AVERY ${ }^{1}$, Messner, em experiéncas com macacos, observou perda de cones e bastonetes nas retinas expostas, semelhante ao desgaste normal das células fotoreceptoras que ocorre com a idade, ou seja, há envelhecimento precoce. Segundo PALUDETTO $^{17}$, a lesão da retina de macacos expostos continuamente por mais de três dias, à luz é irreversível. 


\subsection{Efeitos sobre o trato gastrointestinal}

Alguns autores descrevem o aparecimento de fezes amolecidas e esverdeadas em crianças em fototerapia, embora outros não tenham confirmado este fato ${ }^{1}$. Esta aceleração do trânsito intestinal decorre da presença de pigmentos fotoderivados na bile; tal efeito pode ser benéfico, uma vez que limita a possibilidade de reciclagem enterohepática da bilirrubina.

Cerca de um quarto dos recém-nascidos, segundo $\operatorname{COSTALOS}^{5}$, apresentam diarréia quando em fototerapia.

Baccken, citado por AVERY ${ }^{1}$ e DECURTIS ${ }^{7}$, achou que as altas concentrações de bilirrubina não conjugada, excretadas na bile, inibiriam a lactase intestinal levando à diarréia.

Já Ébbren, citado por DECURTIS ${ }^{7}$, observou que o tempo do trânsılu intestinal seria influenciado pela intensidade da luz e que a má absorção de lactose seria uma complicação excepcional.

Segundo BROWN ${ }^{3}$, a fototerapia aumenta a bilirrubina não conjugada na bile, que inibiria a lactase intestinal; sendo assim, a diarréia seria devida à inibição transitória da lactase intestinal. A diminuição do tempo do trânsito intestinal levaria à diminuição da absorção de água e nutrientes; aumento das fezes verdes amolecidas decorreria do aumento da concentração biliar de bilirrubina não conjugada pela fototerapia e a cor verde seria devida à presença de biliverdina formada pela auto-oxidação da bilirrubina no intestino.

Em seu estudo sobre icterícia e a influência da fototerapia no esvaziamento gástrico, $\operatorname{COSTALOS}^{5}$ concluiu que este é inibido pelas altas concentraçðes séricas de bilirrubina por interferir no metabolismo dos tecidos.

PREIS et alii ${ }^{18}$, em seu estudo com crianças ictéricas submetidas à fototerapia com oclusão ocular, observou distensão abdominal; esta teria sido causada pelo aumento da aerofagia resultante da agitação e choro da criança, conseqưentes a falta de orientação visual adequada ou irritação local pela proteção ocular. Também é possível que a falta de estimulação óptica possa ter efeito direto sobre a função autônoma do trato gastrointestinal nos recém-nascidos.

\subsection{Ganho de peso}

Os recém-nascidos ganham menos peso na primeira semana de vida devido ao aumento das perdas calóricas e hídricas, peso que recuperam nas duas semanas seguintes ${ }^{1}$.

Segundo SILVESTRO et alii ${ }^{21}$, alguns autores assinalaram uma possível influência da fototerapia no crescimento ponderal do recém-nascido durante as primeiras semanas de vida. Se, por um lado, a perda excessiva de peso pode ser atribuída ao aumento das perdas hídricas devidas à perspiração insensivel, à aceleração do trânsito intestinal e à maior demanda de água para a eliminação da bilirrubina, por outro lado, a observação de tardia diminuição do acréscimo ponderal não é explicada somente através do efeito catabólico induzido pela fototerapia; o autor sugere a presença de um possível fator endócrino-metabólico capaz de influenciar o crescimento do recém-nascido submetido à fototerapia, seja durante o tratamento seja nas semanas subseqüentes. 


\section{6.ð. Alterações hormonais}

O hormônio luteinizante (LH) diminui nas 24 a 48 horas após o começo da fótoterapia e aumenta nos 6 a 9 dias após sua interrupção. Em recém-nascidos de pré-termo do sexo feminino há um aumento do hormônio luteinizante e hormônio folículo estimulante (FSH) nas 3 a 4 semanas após o uso da fototerapia e, nos do sexo masculino, só aumenta o hormonio luteinizante. Isto sugere que a luz pode afetar a função hipofisária-gonodal no recém-nascido humano ${ }^{1}$.

Segundo $\mathrm{BOSCO}^{2}$, após a fototerapia há diminuição de triiodotironina $\left(\mathrm{T}_{3}\right)$; a tireoxina $\left(\mathrm{T}_{4}\right)$ permanece igual e há aumento do hormônio tireo-estimulante (TSH).

\subsection{Riboflavina}

Após a fototerapia há diminuição de riboflavina, pois esta é uma vitamina fotossensivel ${ }^{1,17}$.

\subsection{Alterações sanguineas}

De acordo com TOZZI-CIANCARELLI et alii ${ }^{24}$, a fototerapia provoca aumento da taxa de "turn over" plaquetário, levando a contagens menores de plaquetas. Talvez isto resulte de alterações na membrana pela ação direta da fotoxicidade. Supðe-se que a menor sobrevivência plaquetária decorre da sequestraçðo de plaquetas lesadas pelo baço ${ }^{1,12,24}$. As células vermelhas poderiam sofrer aumento na hemólise resultante da perda das enzimas necessárias ao metabolismo e ds funçōes da membrana, mas não há nenhuma evidência concreta de que as células vermelhas sofram com a luz ou tenham algum prejuízo oxidativo sob condições clínic as ${ }^{1}, 12$

\subsection{Nutriçāo parenteral prolongada}

A exposição de aminoácidos à luz no espectro azul provocou diminuição do triptofano e quando foi acrescentada uma solução multivitamínica houve uma diminuição de metionina e histidina ${ }^{1}$.

\subsection{Dano celular}

SPECK et alii $^{23}$, mostraram que a fototerapia é capaz de lesar o DNA de células em cultura. Segundo estes autores, a lesão é maior com a iluminação intermitente do que com a mesma dose de luz ministrada continuamente. Estudaram, também, os efeitos da fototerapia na fertilização e embriogênese, utilizando o ouriço-do-mar: a iluminação do esperma e oócitos produziu embriơes e padrões de clivagem anormais.

\subsection{Sindrome do "baby-bronze"}

E rara e ocorre em recém-nascidos submetidos a fototerapia que apresentam uma taxa aumentada de fração de bilirrubina direta; caracteriza-se pela instalação de uma cor escura, castanho acinzentada na pele, soro e urina ${ }^{11}$. Conforme RAMOS ${ }^{19}$, para Rubaltelli et alii, a etiologia seria uma ligação da porfirina com $\mathrm{Cu}^{++}$e consequiente destruição da primeira pela ação da luz; a cor bronzeada dever-se-ia aos produtos de degradação 
das porfirinas; já para ONISHI et alii, ${ }^{15}$ seria ela decorrente da difícil excreção hepática dos "pigmentos desconhecidos" originários da fototransformação da bilirrubina.

\subsection{Outros efeitos}

Hipocalcemia, diminuição de prostaglandinas, de ácidos graxos não esterifíca-. dos e alteração do metabolismo do triptofano já foram descritos ${ }^{12}$.

Conforme menciona $\mathrm{BROWN}^{3}$, a fototerapia altera a quantidade e a natureza dos metabólitos do triptofano excretados na urina. Isto leva ao aumento dos níveis plasmáticos do hormônio de crescimento.

\subsection{Alteraçôes comportamentais e efeitos sobre a mãe}

Alterações no comportamento neonatal com alteraçסes das funções durante pelo menos duas semanas além do término da fototerapia estão incluídas entre os efeitos colaterais a curto prazo, apesar de tais alteraçōes comportamentais poderem ser atribuídas à fototerapia em si ou à hiperbilirrubinemia ou a ambas ${ }^{16}$.

As crianças expostas à luz contínua mostram sofrer alteração do estado de sono, havendo diminuição do número de horas dormidas/dia. O grupo de Telgrow, citado por KATCHER ${ }^{12}$, observou diminuição da orientação pela escala Brazelton, mas foi incapaz de distinguir o efeito da separação da mãe, da icterícia ou da fototerapia.

SNYDER ${ }^{22}$, num estudo utilizando a escala de Brazelton para avaliação do comportamento neonatal, mostrou alterações no comportamento dos recém-nascidos associados à fototerapia e concluiu que:

- os recém-nascidos tratados com fototerapia têm funções alteradas que duram além do término da fototerapia;

- estas alterações levam à diminuição da capacidade para uma resposta afetiva ótima;;

- a quebra do relacionamento mãe-filho contribui para a persistência da desorganização do sistema nervoso central, associada à hiperbilirrubinemia e à fototerapia.

Ver a criança em fototerapia pode ser extremamente perturbador para a mãe. Em particular, a oclusão ocular pode interferir com o processo de ligação entre mãe e filho.

O uso da luz azul, que confere uma cor cianótica ao recém-nascido, pode ser muito impressionante.

Além disso, a fototerapia provoca separação entre a criança e os pais, quebrando o vínculo mãe-filho e gerando ansiedade.

7. Assistência de enfermagem aos recém-nascidos em fototerapia

A assistência de enfermagem aos recém-nascidos com hiperbilirrubinemia em fototerapia está voltada para os cuidados com o uso da fototerapia em si e a prevenção ou atenuação dos efeitos colaterais a ela associados. 
No berçário do Instituto da Criança usam-se fototerapia de superfície única com se te lâmpadas branca.

$\mathrm{Na}$ assistência de enfermagem, os procedimentos descritos a seguir foram elaborados baseados na prática dos cuidados prestados na unidade acima referida, que se fundamentou nos estudos e efeitos colaterais mencionados anteriormente.

\section{Cuidados com a fototerapia (aparelho)}

- Promover ventilação adequada das lâmpadas pois o superaquecimento na câmara de luz provoca deterioração das mesmas.

- Cobrir as lâmpadas com tampa de acrílico (plexiglass) para proteger as crianças da radiação ultravioleta e de acidentes como queda ou explosão de alguma lâmpada.

- Trocar as lâmpadas cada 2000 horas de uso no caso de luz branca e cada 200 horas de luz azul, ambos perdem seu e feito fotoxidante.

- Medir o fluxo radiante da luz com o aparelho próprio para isso e trocar as lâm. padas quando o fluxo cair abaixo de $4 \mathrm{~W} /\left(\mathrm{cm}^{2} . \mathrm{nm}\right)$.

- Anotar data e hora do início, interrupção e fim da fototerapia para se poder calcular o número de horas de tratamento, tendo-se cuidado de não ultrapassar o limite de horas.

- Observar o estado da incubadora e local da mesma, pois incubadoras descoloridas e em lugares quentes receberão menos luz radiante.

\section{Cuidados com o recém-nascido}

- Manter a criança d̀ distância de aproximadamente $40 \mathrm{~cm}$ das lâmpadas para garantir fluxo radiante ótimo.

- Manter a criança despida, pois a reação de fotoxidação se dá na pele.

- Fazer mudança de decúbito com frequência, pois as partes não expostas à luz permanecerão ictéricas.

- Proteger os olhos e genitais do RN com pano escuro para evitar lesão de retina e possível lesão das células sexuais.

- Cuidar para que a venda ocular não escorregue e cubra as narinas, o que provocaria bloqueio da passagem de ar.

- Desligar a fototerapia e retirar a proteção ocular durante a prestação de cuidados de higiene, a alimentação e o horário de visitas, para a estimulação visual.

- Estimular o aleitamento materno, se possível, para que se possa estabelecer o vínculo mãe-filho.

- Verificar o peso diariamente para se observar evolução ponderal.

- Observar a aceitação da dieta.

- Oferecer aporte hídrico com frequiência para compensar o aumento da perda insensível de água causado pela fototerapia. 
- Observar o gotejamento de NPP ou soro de manutenção, se estiver sendo administrado à criança, para que esta receba o aporte hídrico e calórico adequado.

- Observar o aspecto e o número de evacuaçб̃es.

- Observar o turgor da pele, a umidade das mucosas, a densidade da urina e o volume urinário para avaliar o estado de hidratação da criança.

- Controlar a temperatura e a frequência cardíaca e respiratória frequentemente.

- Observar possíveis efeitos colaterais como: "rash" cutâneo, hipertermia, síndrome do "baby-bronze", hipo ou hiperatividade e distensão abdominal.

\section{Conclusão}

A fototerapia é uma terapêtica amplamente utilizada no tratamento da hiperbilirrubinemia neonatal. A assistência de enfermagem consiste no cuidado com o recémnascido, na prevenção ou atenuação dos efeitos colaterais causados pela fototerapia e no uso apropriado do equipamento, para que a criança permaneça o menor tempo possível em tratamento. Tendo o uso da fototerapia sido iniciado como que ao acaso, muito se tem estudado e muitas pesquisas ainda vêm sendo realizadas para se conhecerem a fundo os princípios e como melhor utilizá-la a fim de que sejam reduzidos os efeitos colaterais.

TURRINI, R.N.T. Nursing care of newborn under phototherapy treatment. Rev. Esc. Enf. USP, São Paulo, 22 (3): 309-321, dec. 1988.

The author did a bibliographic surveying about the mechanism, toxicity and types of lamps used in phototherapy. She described the mursing care that is given to newborns under phototherapy in the nursery of external newborns of the Instituto da Criança do Hospital das Clinicas da Faculdade de Medicina da Universidade de São Paulo.

UNITERMS: Infant newborn. Phototeraphy. Nursing care.

\section{REFERENCIAS BIBLIOGRĀFICAS}

1. AVERY, G.B: Neonatologia: fisiopatologia e cuidado do recém-nascido. 2.ed. Rio de Janeiro, Artes Médicas, 1984, cap. 24, p.481-550.

2. BOSCO, M. et alii. Phototherapy in neonatal hyperbilirubinemia and evaluation of T3, T4 and TSH. Minerva pediatr., Torino, 36 (12):611-15, 1984.

3. BROWN, A.K. Phototherapy for neonatal hyperbilinubinemia : efficacy, mechanism and toxicity, Adv. pediatr., Chicago, 27:341-89, 1980.

4. BRYLA, AK. et alii. Efficacy of phototherapy in prevention and management of neonatal hyperbilirubinemia. Pediatria, Evanston, 75 (2 pt2):393400,1985.

5. COSTALOS, C. Effects of jaunice and phototherapy on gastris emptying in the newborn. Biol. neonate, New York, 46 (2): 57-60, 1984.

6. COSTARINO, A.T. Effects of spectral distribution on isomerization of bilirubin "in vivo". J. Pediat, Rio de Janeiro, 107 (1): 125 8, 1985.

7. DeCURTIS, M. Evidence for secretory type diarrhea in infants treated by phototherapy. Lancet, London, 1 (8277): 909, 1982. 
8. EGGERT, P. et alii. On the distribution of irradiation intensity in phototherapy:measurements of effective irradiance in an incubator. Eur. J. pediatr., Berlin 142 (1):5861, 1984.

9. ENNEVER, J.F. et alii. Phototherapy in neonatal jaundice: optimal wavelenghts of light. J. Pediatr., Washington, 103 (2): 295-99, 1985.

10. GIACOIA, G. \& SMITH, V. Phototherapy in neonatal jaundice: current recomendations. Postgrad. Med., Minea polis, 79 (2) 223-30, 1986.

11. GOSHI, L.H. Fototerapia. In: VAZ, F.A.C. Manual de atendimento do recém-nascido, normais e patológicos. São Paulo, Sarvier, 1986.

12. KATCHER, A.L. Phototherapy. J. Fam. Pract., New York, 14 (6): 1123-38, 1982.

13. MEDONAGH, A.F. et alii. Like a shrivelled blood orange bilirrubin jaundice and phototherapy. Pediatrics, Evanston, 75 (3): 443-5, mar. 1985.

14. MODI, N. \& KEAY, A.J. Phototherapy for neonatal hyperbilirubinemia: the importance of dose. Arch. Dis. Child., London, 58:406-9, 1983.

15. ONISHI, S.A. et alii. Mechanism of development bronze-baby syndrome in neonates treated with phototherapy. Pediatrics, Evanston, 69 (3):2736, 1982.

16. PALUDETTO, R. et alii. Effects of different ways of covering the eyes on behavior of jaundicedinfants treated with phototherapy. Biol. Neonate. Basel, 47 (1): 18, 1985.

17. PALUDETTO, R. et alii. La fototerapia: recenti acquisizioni, indicazioni, limiti. Pediatria, Napoli, 90 (3): 343-55, 1982.

18. PREIS, O. et alii. Abdominal distension in newborns infants on phototherapy - the role of eye occlusion. J. Pediatr., Washington, 94 (5): 816-819, 1979.

19. RAMOS, J.L.A. et alii. Síndrome do recém-nascido bronzeado: descrição de dois casos e reavaliação do problema. Rev. Hosp. Clin. Fac. Med. São Paulo, 39 (2):76-80, 1984.

20. SHARMA, S.K. et alii. Double versus single surface phototherapy in neonatal hyperbilirubinemia. Indian. Pediatr., New Delhi, 22 (3):235-39, 1985.

21. SILVESTRO, L. et alii. Effetto della fototerapia sull'accrescimento ponderale de neonati. Minerva Pediatr., Torino, 37:217-22, 1985.

22. SNYDER, D.M. et alii. Effects of phototherapy on neonatal behavior. Pediatr. Res., Baltimore, $10(4): 432,1976$.

23. SPECK, W.T. Intracellular DNA-modifying potential of phototherapy. Pediatr. Res., Baltimore, $10(4): 432,1976$.

24. TOZZI-CIANCARELLI, M.G. et alii. Photodynamic damage induce by bilinubin on human platelets: possible relevance to newborn pathology. Biol. Neonate., Basel, $48(6): 336-40$, 1985.

25. TUFTS, F. \& JOHNSON, F. Neonatal jaundice and phototherapy. Cancer Nurs., New York, 75 (11):45-7, 1979.

26. VECCHI, C. New light in phototherapy. Lancet, London, 2 (8294): 390, 1982.

27. VECCHI, M.D. et alii. Phototherapy for neonatal, jaundice: clinical equivalence of fluorescent green and "special" blue lamps. J. Pediatr., 108 (3):452 6, 1986.

28. WALTHER, F.I. et alii. Cardic output change in newborns with hiperbilirubinemia treated with phototherapy. Pediatrics, Evanston, 76 (6): 918-21, 1985.

Recebido para publicação em 04.06 .87 